University of Nebraska - Lincoln

DigitalCommons@University of Nebraska - Lincoln

Spring 5-2019

\title{
Critical Wedges and Penetrative Strain: How Does Penetrative Strain Alter the Concept of a Critical Wedge?
}

Nicole L. Smith

University of Nebraska - Lincoln

Follow this and additional works at: https://digitalcommons.unl.edu/envstudtheses

Part of the Environmental Education Commons, Natural Resources and Conservation Commons, and the Sustainability Commons

Disclaimer: The following thesis was produced in the Environmental Studies Program as a student senior capstone project.

Smith, Nicole L., "Critical Wedges and Penetrative Strain: How Does Penetrative Strain Alter the Concept of a Critical Wedge?" (2019). Environmental Studies Undergraduate Student Theses. 226.

https://digitalcommons.unl.edu/envstudtheses/226

This Article is brought to you for free and open access by the Environmental Studies Program at DigitalCommons@University of Nebraska - Lincoln. It has been accepted for inclusion in Environmental Studies Undergraduate Student Theses by an authorized administrator of DigitalCommons@University of Nebraska Lincoln. 
Critical Wedges and Penetrative Strain:

How Does Penetrative Strain Alter the Concept of a Critical Wedge?

An Undergraduate Thesis

Submitted in Partial fulfillment of

Department of Environmental Studeies Degree Requirements

University of Nebraska-Lincoln

\author{
by \\ Nicole L. Smith, BS \\ Environmental Studies and Geology \\ College of Agricultural Sciences and Natural Resources and College of Arts and Sciences
}

May 3, 2019

Faculty Mentors:

Cara Burberry, PhD, Department of Earth and Atmospheric Sciences 


\begin{abstract}
By definition, a critical wedge shows limited internal deformation, and, also by definition, penetrative strain is deformation occurring on a microscale within a deforming rock sequence. Critical wedge theory is typically used to understand the development of fold thrust belts, where variables such as the internal and basal friction, surface taper and dip of the décollement are taken into account. Numerical modeling shows that the minimum stable surface taper is dependent on the basal friction and the overburden, but that there are a range of possible tapers for a stable wedge. This study presents a series of analog models, where the overburden thickness is systematically varied over a constant basal décollement layer. Models are shortened to 5\%,10\% and 15\% respectively, creating a total of 12 experiments. Models were photographed from top and side view at each increment (1\%) of shortening and side view photographs were used to measure surface taper. It was expected that the surface taper would increase with a thinner overburden, and this did occur in early model stages. However, in the latter stages of shortening and in the final configuration, models tended to the same surface taper, within the stable field, accommodated by varying amounts of penetrative strain. A model with a thinner overburden showed an increase in average penetrative strain within the overburden, relative to the comparison model with a thicker overburden from a previous experimental series. These results suggest that whilst critical wedge theory is a valuable construct for understanding the final configuration of a fold-thrust belt, the detailed behavior and development of the wedge cannot be understood without the inclusion of the penetrative strain concept.
\end{abstract}

Key Words: Penetrative Strain, Critical Wedge Theory, Critical Taper 


\section{Acknowledgements}

I was supported in this research by a UCARE grant from the University of Nebraska-Lincoln which allowed me to pursue this project and further my education. I acknowledge an academic license for the MOVE suite from Petroleum Expert. I would also like to dedicate this project to my supportive and amazing advisor Dr. Cara Burberry who always believed in me. 


\section{Introduction}

A complete understanding of the structure of a regional fold-and-thrust belt has been a necessary tool for resource acquisition industries spanning the globe. Innumerable models of fold-and-thrust belt structures have been created for industrial and academic interest by utilizing, in addition to other methods, the critical coulomb wedge theory. The concepts of this theory were first established by Elliott (1976) and Chapple (1978) and were developed further by Davis et al. $(1983)$, Dahlen $(1984,1990)$ and Dahlen et al. (1984). The critical wedge theory, also known as the critical taper model, attributes the wedge of earth created in a fold-and-thrust belt to be comparable to a wedge of soil or snow that forms in front of a moving bulldozer (Davis et al., 1983). When a thin layer of Coulomb material is encountered by the convergent plate boundary, the bulldozer, it deforms by scraping crustal material along a major décollement commonly made of viscous salt or a water saturated, overpressured shale. The material deforms by steepening its surface slope, until a critical angle is reached that allows stable sliding to occur along the base supposedly without continued internal deformation. This critical wedge is the thinnest body that can be thrust over its décollement and is on the verge of brittle failure internally and on its base, the critical state (Davis et al., 1983; Von Hagke et al., 2014). The critical wedge theory utilizes the angle of the basal slope $(\beta)$, the internal friction angle $(\phi)$, and the coefficient of basal friction $\left(\mu_{\mathrm{b}}\right)$ to determine the critical angle $(\alpha+\beta)$ that the structure will adhere to. It is represented by the equation:

$\alpha+\beta=((1-\sin \phi) /(1+\sin \phi))\left(\beta+\mu_{b}\right)$

This critical wedge method can be consistently relied on to determine the critical angle of a deforming accretionary wedge and to measure macroscale deformation in the rocks. This macroscale deformation occurs primarily as thrust faults throughout the structure and as the creation of new synclinal structures. Once sufficient time has passed to create the critical wedge, the fold-thrust belt reaches a virtually stable state with the surface taper angle oscillating slightly around the calculated critical angle. However before adequate time has passed to reach this stable state, the fold-thrust structure experiences internal deformation on the microscale that has yet to be accounted for in the critical wedge theory. In addition, a common misconception of the critical wedge theory is that, as new material is accreted at the toe of the wedge, the wedge is believed to grow self-similarly in that the wedge at time $2 t$ is indistinguishable from 
the wedge at time $t$ (Dahlen, 1990; Davis et al., 1983). It is also thought that, in order to maintain its critical angle, the wedge will fail only along normal faults or internal thrust faulting to decrease its surface angle (Davis and Engelder, 1985; Ruh et al., 2012).

Although it is likely that a critical wedge does accommodate the influx of new material by the development of macroscale deformation structures including thrust faults and synclinal folds, Davis et al. (1983) state that a critical wedge that is accreting fresh material also deforms internally to accommodate new material and maintain its critical angle. However, this internal deformation is frequently overlooked, because of its absence from the calculated critical angle equations which were created with the thinnest critical wedge proportions in mind not the continually accreted material wedge, causing some authors to question the validity of the critical wedge theory as applied to fold-and-thrust belts (e.g. Woodward, 1987). In addition, Experiment 1 from the GeoMOD 2008 series (Schreurs et al., 2016) shows that even a supposedly "stable sliding" wedge undergoes deformation at the toe. This experiment set up a wedge with a horizontal base and a surface taper at or close to critical, and monitored the deformation as the wedge was moved forward. In all cases, deformation occurred at the toe of the wedge, steepening the taper of the wedge at the toe. This implies that, at the very least, the phenomenon of stable sliding on a horizontal base cannot be adequately described by the critical wedge theory or reproduced in a laboratory. here propose that a proportion of the "missing" internal deformation is in fact taken up by penetrative strain. Simply stated, penetrative strain is the proportion of total shortening that is not accommodated by macroscale folds and thrusts. Penetrative strain may be accommodated by a combination of intragranular deformation that include: twinning, dislocation glide and creep or the development of other strain fabrics, and intergranular processes such as stylolitization, cleavage development, or grain impingement. I have run a series of 12 experiments with different overburden thicknesses over a weak basal décollement and demonstrate that deformation by penetrative strain is still occurring even in the "stable sliding" field of wedge development.

\section{Materials and Methods}

This study presents a series of analog models, where the overburden thickness is systematically varied over a constant basal décollement layer. Mulugeta (1988) demonstrated that analog modeling gives results consistent with cohesionless Coulomb theory and wedge taper, whereas when cohesion was a considerable component of the strength of the material, the length scale has to be carefully controlled. 
Following these findings, I am using loose sand, and the basic design for this experiment was modeled after a previous penetrative strain study (Burberry, 2015).

The behavior of a brittle sand pack over a basal décollement layer was modeled using an analog box setup comprised of a box with one moving wall driven by a stepper motor and two cameras set up and leveled to photograph the top and side views of the models. The model apparatus is $48 \mathrm{~cm}$ wide and had an initial starting length of $64 \mathrm{~cm}$ in every experiment. The box base, moving wall, and fixed wall were made of waterproofed, lacquered plywood and the sides were made of glass. The sides of the apparatus were not lubricated, as the model was wide enough to obtain results from the center of the box that were free from edge effects caused mainly by friction. The standard rule for avoiding edge effects is to use a section of the model greater than or equal to the height of the sedimentary wedge (Burberry, 2015). Representative slices were sliced between 8 and $40 \mathrm{~cm}$ across the apparatus, leaving a margin of $8 \mathrm{~cm}$ on each side that was affected by edge effects, and $32 \mathrm{~cm}$ that can be used for analysis (Figure 1a). The motor that powers the moving wall is capable of driving the wall at various constant rates between 4 and $8 \mathrm{~mm} / \mathrm{h}$. Models are run at a constant speed of $8 \mathrm{~mm} / \mathrm{h}$. The apparatus was cleaned and allowed to dry between experiments.

A total of 12 analog models were performed to examine how penetrative strain accommodation varies with assorted overburden thickness in a contractional system with a salt décollement. Each model had the same set up but with varied layers of uncolored sand. A $5 \mathrm{~mm}$ thick silicon polymer with dimensions of $58 \mathrm{~cm}$ by $45 \mathrm{~cm}$ was laid in the analog box the previous night and given time to spread uniformly. Fine uncolored sand was poured into layers over this silicon polymer and smoothed evenly with a scraper but not compacted (Figure 1b). The sand was sifted with a \#35 standard test sieve to remove sand grains larger than $0.5 \mathrm{~mm}$. Thin marker layers of red and black were used to separate uncolored sand layers and to track deformation of model. A grid pattern of black or red colored sand was positioned on top of the model to record developing strain patterns in the foreland area during each model run. Each model was shortened to either $5 \%, 10 \%$, or $15 \%$ of the original length. Two analog models, Model 5 and Model 7 , were used to obtain surface angles while being run but were not used to calculate penetrative strain because one was extended before being compressed and the other was compressed past the total shortening desired.

This series of analog models is not intended to model a specific natural setting. It was intended to be a simplified system that tracks penetrative strain development with varied overburden thickness and produces observable critical angles of each critical wedge, the results of which can be potentially applied 
to many different settings. Brittle sedimentary rock units are represented in analog modeling by rounded, fine-grained quartz sand which demonstrates little elastic deformation. The fine-grained sand layers and the tinted fine-grain marker layers were tested in Burberry (2015) to be mechanically similar, following the Krantz (1991) methodology. The fine-grained sand was measured to have an internal friction coefficient of 0.59 and an angle of internal friction of $30.5^{\circ}$ by a modified Hubbert apparatus (Hubbert, 1937). The sand size and model thickness for the $1: 3$ ratio model setup results in a $150 \mathrm{~mm}$ thick sand pack comprised of about 300 grains of sand finer than $0.5 \mathrm{~mm}$. This signifies that each sand grain represents $5 \mathrm{~m}$ length clasts in nature when the model is scaled up to $1 \mathrm{~km}$ in nature equaling $1 \mathrm{~cm}$ in the model. Due to this oversimplified scaling relationship, the calculated model results are assumed to be underestimates of the natural situation.

A silicon polymer, Xiameter RBG-0901, was used to model the behavior of a salt detachment layer. Xiameter RBG-0901 is produced by Dow Corning and is a Newtonian viscous material. It has a viscosity of $\sim 2$ * $104 \mathrm{~Pa} \mathrm{~s}$ at room temperature, a density of $0.97 \mathrm{~g} \mathrm{~cm}-3$, and strain rates of 10-5-10-3 s-1, representing rock salt (Jackson and Talbot, 1991; Warsitzka et al., 2013). Similar to rock salt, the silicon is incompressible. This silicon can simulate salt in a natural setting, such as the Zagros Mountains, Iran (Bonini, 2003; Warsitzka et al., 2013).

Photographs were taken of side views and top views throughout each model run at the initial length, every $1 \%$ shortening, and at the final length. The top view images were used to measure the width of the foldthrust belt. The side view images were used to track and determine the critical angle development at every $1 \%$. These images were inputted into Corel Draw where the critical angle was measured from the front of the foreland zone to the moving back wall.

After each model completed the desired shortening (Table 1), a sand pack was added to protect the surface topography, the entire model and sand pack was wetted with a soap solution, and sliced into cross sections. A low-pressure garden sprayer was used to wet the sand so as to not affect the sand grains orientations. A large flat-bladed knife was used to cut the model and with some skill the strain structures were not affected when cut into cross sections. The model was cut at every $8 \mathrm{~cm}$ and $10 \mathrm{~cm}$ and photographs were taken of each. The best photographs of each model were used as representative cross sections and inputted into MOVE. MOVE was used to restore the deformation structures of the fold thrust belt to the original flat layer orientation. Through unfaulting and unfolding algorithms, thrust faults were restored by connecting the hanging wall and foot wall marker layers and fold structures were straightened while line length was preserved. This produced a restored model length for each marker length that could 
then be compared to the original undeformed length; the difference between the restored and deformed length is tectonic shortening given in millimeters. The difference between the tectonic shortening in $\mathrm{mm}$ and the imposed, known total shortening is the amount of shortening due to penetrative strain. This restoration process is represented in a graphic (Burberry 2015, her Figure 4). The anticipated error in linelength restoration is comparatively small since the factors of the experiments including stratigraphic thickness, depth to the décollement, and the absence of erosion are controlled (Judge and Allmendinger, 2011); therefore, discrepancies in line-length are expected to be due to penetrative strain.

It is assumed that plane strain is only operating within these models since the apparatus and setup inhibited out-of-plane movement in the central region of the model which was unaffected by edge effects. The amount of total shortening produced by penetrative strain is the difference between the calculated tectonic shortening and the known total shortening. Volume loss caused by sand and silicon escape is considered negligible due to the tight fit of the moving wall with the sides and base of the model apparatus. Any discrepancies between the calculated tectonic shortening and total shortening are considered to be caused by penetrative strain.

Penetrative strain deformation in these models is caused by compaction of grains, grain rotation, and a decrease in pore space caused by model setup. This represents a simplification of penetrative strain since in a natural brittle system many other mechanisms may accommodate penetrative strain such as twinning and grain impingement, clast rotation, and loss of pore space. The penetrative strain calculated for each model takes only loss of pore space into account and is, therefore, an underestimation of the true penetrative strain.

\section{Results}

\section{1:1 ratio, silicon to sand layers}

The only 1:1 ratio of silicon layer to sand model was Model 1 . Model 1 was shortened $1.95 \mathrm{~cm}$ to a total shortening of $3 \%$ which was the maximum shortening that could be performed without silicon escaping to the surface, causing a loss of volume. I was unable to calculate a meaningful volume loss due to penetrative strain for this experiment and the remainder of this contribution will not include a discussion of this experiment. 


\section{1:2 ratio, silicon to sand layers}

The models assembled with a 1:2 ratio of silicon layer to sand layers were Model 2, Model 3, and Model 6 (Figure 3). Model 3 was shortened $3.1 \mathrm{~cm}$ to a total shortening of $5 \%$. One pop up structure developed close to the moving back wall, and some embryonic buckling develops outboard of this clearly developed structure (Figure $3 a, b)$. The percent shortening due to penetrative strain is $73.3 \%$. The width of the fold belt is $9.7 \mathrm{~cm}$. Model 2 was shortened $6.0 \mathrm{~cm}$ to a total shortening of $10 \%$. Two pop up structures develop in this model, with some embryonic buckling outboard of these structures (Figure 3c, d). The percent shortening due to penetrative strain is $71.3 \%$. The width of the fold belt is $11.5 \mathrm{~cm}$. Model 6 was shortened $7.1 \mathrm{~cm}$ to a total shortening of $11 \%$ which was the maximum shortening that could be performed without a loss of volume; that is, without silicon escape at the surface. In this model, two backthrusts developed, close to the moving wall, followed by a symmetric pop up structure in the foreland (Figure $3 e, f)$. The percent shortening due to penetrative strain is $35.8 \%$. The width of the fold belt is $13.8 \mathrm{~cm}$. These values are summarized in Table 2.

The surface angles collected from the 1:2 ratio models (Figure $2 \mathrm{~A}$ ) fall within the rising value zone until $4 \%$ to $5 \%$ total shortening where a fall in surface angle occurs which correlates with the development of a new fold. This fall occurs till $6 \%$ total shortening when the angles becomes relatively stable with another drop, although much smaller, occurring at the $8 \%$ and correlating with the development of another fold.

\section{1:3 ratio, silicon to sand layers}

The models assembled with a 1:3 ratio of silicon layer to sand layers were Model 4, Model 8, and Model 12 (Figure 4). Model 12 was shortened $3.2 \mathrm{~cm}$ to a total shortening of $5 \%$. Two small fold structures developed, one with a significant amount of asymmetry. The percent shortening due to penetrative strain is $44.1 \%$. The width of the fold belt is $12.5 \mathrm{~cm}$. Model 4 was shortened $6.4 \mathrm{~cm}$ to a total shortening of $10 \%$. Two large pop up structures develop, one verging to the hinterland, and one which is symmetric. The percent shortening due to penetrative strain is $39.7 \%$. The width of the fold belt is $14.6 \mathrm{~cm}$. Model 8 was shortened $9.6 \mathrm{~cm}$ to a total shortening of $15 \%$. Three thrust structures develop, one verging to the foreland, overriding the intervening syncline, and two verging to the hinterland. The silicon layer becomes very thick beneath these structures and thins to the foreland. The percent shortening due to penetrative strain is $46.8 \%$. The width of the fold belt is $20.1 \mathrm{~cm}$. 
In addition to the surface angles collected from the 1:3 ratio models Model 4, Model 8 , and Model 12, the surface angles from Model 5 and Model 7 were included in Figure 2B and 2C. These models were not utilized in calculating penetrative strain and width of the fold belt due to one model being extended before compression and the other model being compressed past the $15 \%$ shortening. The model surface angles were split into two different charts, Figure $2 \mathrm{~B}$ and Figure $2 \mathrm{C}$, due to the pictures being taken at different angles. The surface angles of earlier models, Model 4 and Model 5, found in Figure 2B fall within the rising value zone until $3 \%$ to $5 \%$ total shortening where a fall in surface angle occurs to each. Model 4 decrease in surface angle correlates with the development of a new fold. The Model 5 fall occurs from $3 \%$ to $4 \%$ total shortening. The Model 4 fall occurs from $5 \%$ to $6 \%$ total shortening after which the angle becomes relatively stable but has a slight increase in surface angle till the final $10 \%$ total shortening. The surface angles of later models, Model 7, Model 8, and Model 12, found in Figure 2C are within the rising value zone until $4 \%$ total shortening where all model surface angles fall in values. This decrease in surface angles occurs till $6 \%$ to $7 \%$ total shortening with Model 7 and Model 8 entering the stable zone. Model 7 remains stable without much change in surface angle. Model 8 decreases surface angle till $7 \%$ total shortening and increases till $9 \%$ total shortening. At $9 \%$ total shortening, another, but smaller than the first, decrease in surface angle occurs which correlates with the development of a new thrust-cored fold.

\section{1:4 ratio silicon to sand layers}

The models assembled with a 1:4 ratio of silicon layer to sand layers were Model 9, Model 10, and Model 11. Model 10 was shortened $3.2 \mathrm{~cm}$ to a total shortening of $5 \%$. One fold structure developed, verging to the foreland. The percent shortening due to penetrative strain is $51.5 \%$. The width of the fold belt is 14.0 $\mathrm{cm}$. Model 9 was shortened $6.4 \mathrm{~cm}$ to a total shortening of $10 \%$. Two fold-thrust structures developed, one verging to the foreland and one to the hinterland. Between them, they override the intervening syncline. The percent shortening due to penetrative strain is $23.9 \%$. The width of the fold belt is $19.4 \mathrm{~cm}$. Model 11 was shortened $9.6 \mathrm{~cm}$ to a total shortening of $15 \%$. Two fold-thrust structures develop, overriding the intervening syncline as in Model 9. To the foreland, a third, symmetric, pop up structure developed. The percent shortening due to penetrative strain is $30.6 \%$. The width of the fold belt is 23.9 $\mathrm{cm}$.

The surface angles collected from the 1:4 ratio models (Figure 2D) fall within the rising value zone until $6 \%$ to $7 \%$ total shortening where a fall in surface angle occurs which correlates with the development of 
a new fold. This fall occurs till $8 \%$ total shortening when the angles becomes relatively stable. The angle of Model 11 increases slightly in the stable zone till another drop, although much smaller than the first, occurring at the $13 \%$ and correlating with the development of another fold.

\section{Results summary}

All model series showed three very clear characteristics, (1) an increase in width of the fold-thrust belt with the addition of fold structures as shortening progressed and thrusts developing in the hinterlandmost fold structures, (2) the pattern of steepening surface taper, an abrupt drop in taper and then stability in surface taper and (3) the accumulation of penetrative strain throughout the duration of the experiment. Models also showed increasing width of the fold-thrust belt with increasing thickness of overburden. In models with a 1:2 or 1:3 ratio of overburden to décollement thickness, the drop in surface taper occurred at about $4 \%$ bulk shortening, and in the $1: 4$ ratio model this drop occurred about $6 \%$ bulk shortening, although the stable surface angle is approximately the same in all models (Figure 2). Thin models showed higher penetrative strain than thick models, as summarized in Table 2.

\section{Comparison to a natural example}

The methodology to calculate penetrative strain has been applied to a cross section from the Fars zone of the Zagros fold-thrust belt (McQuarrie, 2004) in order to assess the amount of extra shortening that should be considered when analyzing this region. The Zagros fold-thrust belt was created from the continent-continent collision of the Eurasian and Arabian margin during the Tertiary Period (e.g. Alavi, 1994; Hessami et al., 2006; McQuarrie, 2004; Mouthereau, et al., 2006). The Fars Province is located in the southeast section of the where the deformation area is composed of large periodic folding of the Meso-Cenozoic sedimentary cover over the Cambrian Hormuz Formation basal salt layer (Alavi, 2004; Blanc et al., 2003; Mouthereau et al., 2006). In the Zagros cross-section as shown in Figure 6, digitized after McQuarrie (2004), the Hormuz salt is between $\sim 3$ and $\sim 4 \mathrm{~km}$ thick, with an overburden of between $\sim 9$ and $\sim 16 \mathrm{~km}$, measured at the SW and NE end of the cross-section respectively. This means that the models run at 1:3 and 1:4 ratios of overburden to salt are acceptable comparisons to the natural example. McQuarrie (2004) records $\sim 20 \%$ tectonic shortening $(67 \mathrm{~km})$; therefore I am making comparisons to our $15 \%$ bulk shortening models as the closest available. Our models predict between 35 and $46 \%$ penetrative strain for the range of overburden to décollement ratios in this example, thus the $67 \mathrm{~km}$ tectonic 
shortening is between $54-65 \%$ of the total shortening. Using the simple relationship "shortening due to PS/tectonic shortening = \% shortening due to PS/\% tectonic shortening" I would predict between $57 \mathrm{~km}$ and $36 \mathrm{~km}$ additional shortening due to penetrative strain across this cross-section for the Fars Zone in the Zagros of Iran. It should be noted that Ruh et al., (2012) considered how the additional presence of the $\sim 800 \mathrm{~m}$ thick Gachsaran evaporate layer to the Hormuz evaporate could favor folding rather than faulting deformation in the Zagros due to the possibility of flexural slip. I have considered only the Hormuz formation as the basal décollement and not an intermediate décollement relationship. I have also followed the cross-section of McQuarrie (2004) rather than the findings of Mouthereau et al., (2006) and have not included a basement wedge in the restored cross-section of the Fars Province.

\section{Discussion}

All models developed the classic pop up structures that are expected above a salt décollement, together with the shallow forethrusts and steeper backthrusts, wide deformation belt, and low taper predicted by previous work and theory (Agarwal and Agrawal, 2002; Buiter, 2012; Costa and Vendeville, 2002; Ellis, 2004; Huiqi et al., 1992). All models that were shortened to more than $5 \%$ develop a critical, or stable taper, thus I suggest that some part of the ongoing deformation within the wedge discussed by Del Castello et al. (2004) and Storti and McClay (1995) and required by Woodward (1987) is being accommodated by the ongoing accumulation of penetrative strain, which will be discussed in more detail below.

The three surface angle developmental stages that were observed and categorized in Figure 2 emphasize the presence of internal deformation occurring in the critical wedge as new material is accreted. The first stage, labelled Rise on Figure 2, correlates with an increasing in surface angle as the critical wedge develops and constitutes its critical angle through internal deformation and the first macroscale anticlinal fold for all models. The 1:2 and 1:3 ratio models demonstrated a similar total shortening amount (3\% to $5 \%$ ) needed to finish the first stage of angle development. The $1: 4$ ratio models required $6 \%$ to $7 \%$ total shortening before this first stage of development was completed. This longer time frame for the 1:4 ratio model was likely due to the increased overburden and additional deformation that it had to undergo. The second stage of surface angle development was not labeled on Figure 2 but was referred to as the fall in surface angle. This rapid decrease in surface angle, up to $10^{\circ}$ for several models, occurred over a $1 \%$ to 
$2 \%$ total shortening frame for all models and each fall correlated with the formation of a new anticlinal fold. The third stage of the surface angle development, labelled Steady on Figure 2, correlates with a relatively steady state where the surface angle does not drastically increase or decrease but remains stable after the initial development of the critical angle. This final stable state does demonstrate continued internal deformation in most of the models that were shortened to $10 \%$ or $15 \%$ total shortening in order to maintain the critical angle as new material is added through a slight increase in the surface angle till the next anticlinal fold development. The next anticlinal fold development corresponds with another dip in the surface angle although much smaller than the first. The best examples of this occurring are Model 8 and Model 11. The only model that does not show this slight increase in surface angle after the initial fall is Model 7 which remains extremely constant in its surface angle after the initial drop to its complete shortening of $15 \%$.

The penetrative strain sequences that were calculated for the 1:2 ratio, 1:3 ratio, and 1:4 ratio models, shown in Table 2 and Figure 7a, each had a distinctively different trend. These trends are compared to the penetrative strain sequences found in the 1:3 silicon to sand ratio experiments performed in Lathrop and Burberry (2017) and the fully sand experiments performed in Burberry (2015). It is apparent that the 1:2 ratio calculated penetrative strain sequence is closer to the ductile scenario that Lathrop and Burberry (2017) calculated (Figure 7b). The 1:2 ratio model setup is unstable due to its high proportion of silicon (salt) this is observed through its extremely high calculated percent penetrative strain start values (71.3\% and $73.3 \%$ ) and the rapid decrease to $35.8 \%$ calculated percent penetrative strain at $11 \%$ total shortening. The 1:4 ratio calculated penetrative strain sequence is closer to the brittle scenario from Burberry 2015 due to its increased overburden ratio of sand and is more stable due to its low silicon ratio. The 1:3 ratio calculated penetrative strain sequence demonstrates traits of both the ductile and brittle scenarios and creates a hybrid between the $1: 2$ ratio and 1:4 ratio, but portrays more stability than the 1:2 ratio model setup.

It is possible that models that have an underlying ductile décollement may have a maximum value for the amount of tectonic shortening accommodated by penetrative strain. This value would be in the $35 \%$ to $50 \%$ range since the $1: 3$ ratio and 1:4 ratio models remain in this range and the $1: 2$ ratio model setup drops into this range at $11 \%$ total shortening. The $1: 2$ ratio model value drop at $11 \%$ supports this hypothesis since it drastically drops off into this range at its maximum total shortening. Further studies would need to be conducted on this matter to confirm or deny if there is a maximum amount of tectonic 
shortening due to penetrative strain possible for a given model and if this is a result of model limitations.

\section{Conclusions}

The twelve analog models in this study have demonstrated that: (1) internal deformation in addition to macroscale deformation continues through the accretion of new material on a critical wedge; (2) penetrative strain is accommodated at every stage of critical wedge development since penetrative strain was observed to be present in every model; (3) penetrative strain can be used to measure a fraction of the internal deformation that a critical wedge undergoes; (4) increasing overburden thickness causes the salt décollement system to develop increasingly similar to a frictional décollement scenario; and (5) there may be a maximum amount of tectonic shortening due to penetrative strain possible for ductile décollement analog models.

Few analyses have included penetrative strain into restorations of fold-and-thrust belts. The further analysis of the cross section of the Zagros fold-thrust belt is an ideal example of how the addition of penetrative strain to account for a part of the internal deformation that occurred can improve the calculation of the total shortening. By combining the critical wedge theory calculated equations with calculated penetrative strain, a more accurate representation of the true total shortening of an orogeny can be obtained.

Table 1: Model setup parameters for all models run in this study. $\mathrm{X}$ marks models not used in penetrative strain analysis.

\begin{tabular}{|c|c|c|c|}
\hline \multicolumn{4}{|c|}{ Table 1 } \\
\hline Model & $\begin{array}{c}\text { Ratio of Silicon to Sand } \\
\text { Model Setup }\end{array}$ & $\begin{array}{c}\text { Displacement of back } \\
\text { wall }(\mathrm{mm})\end{array}$ & Total Shortening (\%) \\
\hline $1(\mathrm{X})$ & $1: 1$ & 19.5 & 3 \\
\hline 2 & $1: 2$ & 60 & 10 \\
\hline 3 & $1: 2$ & 31 & 5 \\
\hline 4 & $1: 3$ & 64 & 10 \\
\hline $5(\mathrm{X})$ & $1: 3$ & 31 & 5 \\
\hline
\end{tabular}




\begin{tabular}{|c|c|c|c|}
\hline 6 & $1: 2$ & 71 & 11 \\
\hline $7(\mathrm{X})$ & $1: 3$ & 98 & 15 \\
\hline 8 & $1: 3$ & 96 & 15 \\
\hline 9 & $1: 4$ & 64 & 10 \\
\hline 10 & $1: 4$ & 32 & 5 \\
\hline 11 & $1: 4$ & 96 & 15 \\
\hline 12 & $1: 3$ & 32 & 5 \\
\hline
\end{tabular}

Table 2: Fold-thrust belt width and penetrative strain for all models. Note that models 1, 5, 7 are excluded because no PS calculations were made for these models.

\begin{tabular}{|l|l|l|l|l|}
\hline Model & Silicon:sand ratio & Shortening & FTB width & Average PS \\
\hline 3 & $1: 2$ & $5 \%$ & $9.7 \mathrm{~cm}$ & $73.3 \%$ \\
\hline 2 & $1: 2$ & $10 \%$ & $11.5 \mathrm{~cm}$ & $71.3 \%$ \\
\hline 6 & $1: 2$ & $11 \%$ & $13.8 \mathrm{~cm}$ & $35.8 \%$ \\
\hline 12 & $1: 3$ & $5 \%$ & $12.5 \mathrm{~cm}$ & $44.1 \%$ \\
\hline 4 & $1: 3$ & $10 \%$ & $14.6 \mathrm{~cm}$ & $39.7 \%$ \\
\hline 8 & $1: 3$ & $15 \%$ & $20.1 \mathrm{~cm}$ & $46.8 \%$ \\
\hline 10 & $1: 4$ & $5 \%$ & $14.0 \mathrm{~cm}$ & $51.5 \%$ \\
\hline 9 & $1: 4$ & $10 \%$ & $19.4 \mathrm{~cm}$ & $23.9 \%$ \\
\hline 11 & $1: 4$ & $15 \%$ & $23.9 \mathrm{~cm}$ & $30.6 \%$ \\
\hline
\end{tabular}




\section{References}

Agarwal, K. K., \& Agrawal, G. K. (2002). Analogue sandbox models of thrust wedges with variable basal frictions. Gondwana Research, 5(3), 641-647.

Alavi, M. (1994). Tectonics of the Zagros orogenic belt of Iran: new data and interpretations. Tectonophysics, 229(3-4), 211-238.

Alavi, M. (2004). Regional stratigraphy of the Zagros fold-thrust belt of Iran and its proforeland evolution. American journal of science, 304(1), 1-20.

Blanc, E. P., Allen, M. B., Inger, S., \& Hassani, H. (2003). Structural styles in the Zagros simple folded zone, Iran. Journal of the Geological Society, 160(3), 401-412.

Bonini, M. (2003). Detachment folding, fold amplification, and diapirism in thrust wedge experiments. Tectonics, 22(6).

Buiter, S. J. (2012). A review of brittle compressional wedge models. Tectonophysics, 530, 1-17.

Burberry, C. M. (2015). Spatial and temporal variation in penetrative strain during compression: Insights from analog models. Lithosphere, 7(6), 611-624.

Chapple, W. M. (1978). Mechanics of thin-skinned fold-and-thrust belts. Geological Society of America Bulletin, 89(8), 1189-1198.

Costa, E., \& Vendeville, B. C. (2002). Experimental insights on the geometry and kinematics of fold-andthrust belts above weak, viscous evaporitic décollement. Journal of Structural Geology, 24(11), 17291739.

Cruz, L., Malinski, J., Wilson, A., Take, W. A., \& Hilley, G. (2010). Erosional control of the kinematics and geometry of fold-and-thrust belts imaged in a physical and numerical sandbox. Journal of Geophysical Research: Solid Earth, 115(B9).

Dahlen, F. A., Suppe, J., \& Davis, D. (1984). Mechanics of fold-and-thrust belts and accretionary wedges: Cohesive Coulomb theory. Journal of Geophysical Research: Solid Earth, 89(B12), 10087-10101.

Dahlen, F. A. (1990). Critical taper model of fold-and-thrust belts and accretionary wedges. Annual Review of Earth and Planetary Sciences, 18(1), 55-99.

Dahlen, F. A. (1984). Noncohesive critical Coulomb wedges: An exact solution. Journal of Geophysical Research: Solid Earth, 89(B12), 10125-10133.

Davis, D. M., and Engelder, T. (1985). The role of salt in fold-and-thrust belts. Tectonophysics, 119, 67-88.

Davis, D., Suppe, J., \& Dahlen, F. A. (1983). Mechanics of fold-and-thrust belts and accretionary wedges. Journal of Geophysical Research: Solid Earth, 88(B2), 1153-1172.

Del Castello, M., Pini, G. A., \& McClay, K. R. (2004). Effect of unbalanced topography and overloading on Coulomb wedge kinematics: Insights from sandbox modeling. Journal of Geophysical Research: Solid Earth, 109(B5). 
Elliott, D. (1976). A Discussion on natural strain and geological structure-The energy balance and deformation mechanisms of thrust sheets. Phil. Trans. R. Soc. Lond. A, 283(1312), 289-312.

Ellis, S., Schreurs, G., \& Panien, M. (2004). Comparisons between analogue and numerical models of thrust wedge development. Journal of Structural Geology, 26(9), 1659-1675.

Hessami, K., Nilforoushan, F., \& Talbot, C. J. (2006). Active deformation within the Zagros Mountains deduced from GPS measurements. Journal of the Geological Society, 163(1), 143-148.

Hubbert, M. K. (1937). Theory of scale models as applied to the study of geologic structures. Bulletin of the Geological Society of America, 48(10), 1459-1520.

Huiqi, L., McClay, K. R., \& Powell, D. (1992). Physical models of thrust wedges. In Thrust tectonics (pp. 7181). Springer, Dordrecht.

Judge, P. A., \& Allmendinger, R. W. (2011). Assessing uncertainties in balanced cross sections. Journal of Structural Geology, 33(4), 458-467.

Krantz, R. W. (1991). Measurements of friction coefficients and cohesion for faulting and fault reactivation in laboratory models using sand and sand mixtures. Tectonophysics, 188(1-2), 203-207.

Koyi, H. (1995). Mode of internal deformation in sand wedges. Journal of Structural Geology, 17(2), 293300.

Lathrop, B. A., \& Burberry, C. M. (2017). Accommodation of penetrative strain during deformation above a ductile décollement. Lithosphere, 9(1), 46-57.

McClay, K. R., \& Whitehouse, P. S. (2004). Analog modeling of doubly vergent thrust wedges. Thrust tectonics and hydrocarbon systems: AAPG Memoir 82, p. 184-206

McQuarrie, N. (2004). Crustal scale geometry of the Zagros fold-thrust belt, Iran. Journal of Structural Geology, 26(3), 519-535.

Mouthereau, F., Lacombe, O., \& Meyer, B. (2006). The Zagros folded belt (Fars, Iran): constraints from topography and critical wedge modelling. Geophysical Journal International, 165(1), 336-356.

Mulugeta, G. (1988). Modelling the geometry of Coulomb thrust wedges. Journal of Structural Geology, 10(8), 847-859.

Ruh, J. B., Kaus, B. J., \& Burg, J. P. (2012). Numerical investigation of deformation mechanics in fold-andthrust belts: Influence of rheology of single and multiple décollements. Tectonics, 31(3).

Schreurs, G., Buiter, S.J.H., Boutelier, J., Burberry, C., Callot, J.-P., Cavozzi, C., Cerca, M., Chen, J-H., Cristallini, E., Cruden, A.R., Cruz, L., Daniel, J-M., Da Poian, G., Garcia, V.H., Gomes, C.J.S., Grall, C., Guillot, Y., Guzman, C., Hidavah, T.N., Hilley, G., Klinkmuller, M., Koyi, H.A., Lu, C-Y., Maillot, B., Meriaux, C., Nilfouroushan, F., Pan, C-C., Pillot. D., Portillo, R., Rosenau, M., Schellart, W.P., Schlische, R.W., Take, A., Vendeville, B., Vergnaud, M., Vettori, M., Wang, S-H., Withjack, M.O., Yagupsky, D. \& Yamada, Y., Benchmarking analogue models of brittle thrust wedges. Journal of Structural Geology v. 92, p 116-139

Storti, F., \& McClay, K. (1995). Influence of syntectonic sedimentation on thrust wedges in analogue models. Geology, 23(11), 999-1002. 
Von Hagke, C., Oncken, O., \& Evseev, S. (2014). Critical taper analysis reveals lithological control of variations in detachment strength: An analysis of the Alpine basal detachment (Swiss Alps). Geochemistry, Geophysics, Geosystems, 15(1), 176-191.

Warsitzka, M., Kley, J., \& Kukowski, N. (2013). Salt diapirism driven by differential loading-Some insights from analogue modelling. Tectonophysics, 591, 83-97.

Woodward, N. B. (1987). Geological applicability of critical-wedge thrust-belt models. Geological Society of America Bulletin, 99(6), 827-832. 


\section{Figures}

Figure 1: Model setup. a) top view of the model setup showing the location of the silicon sheet; b) side view of the model setup showing silicon sheet and variable thickness of the overburden sand pack.

a

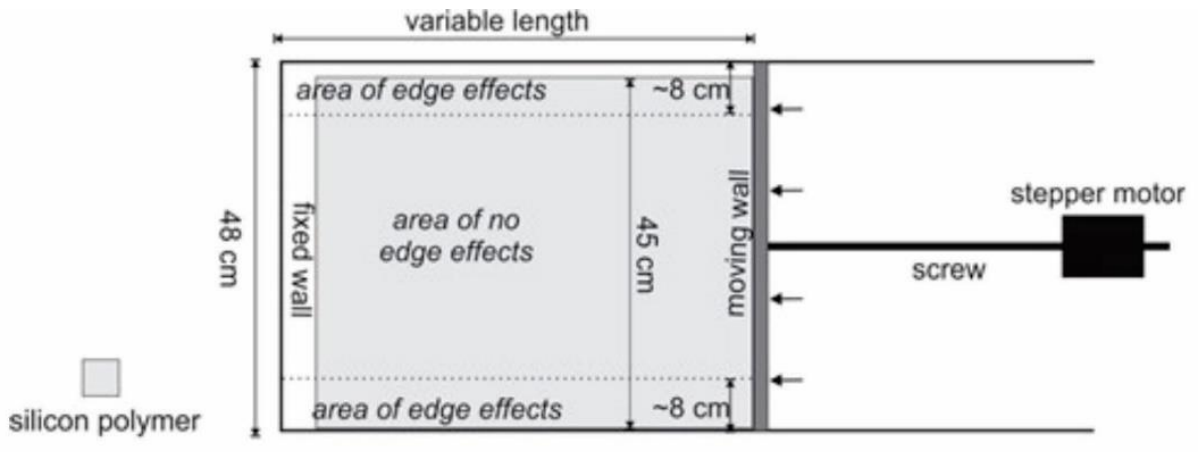

side-view camera

b

fixed wall

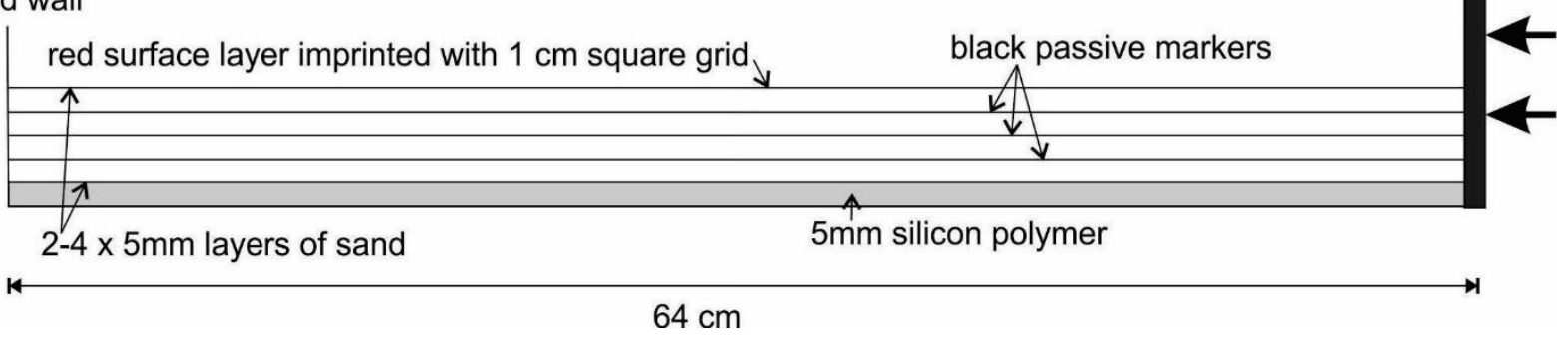


Figure 2: Graphs showing the evolution of the surface taper for each of models 2-12. The lower row of dots marks the initiation of a new fold in the evolution of the models.
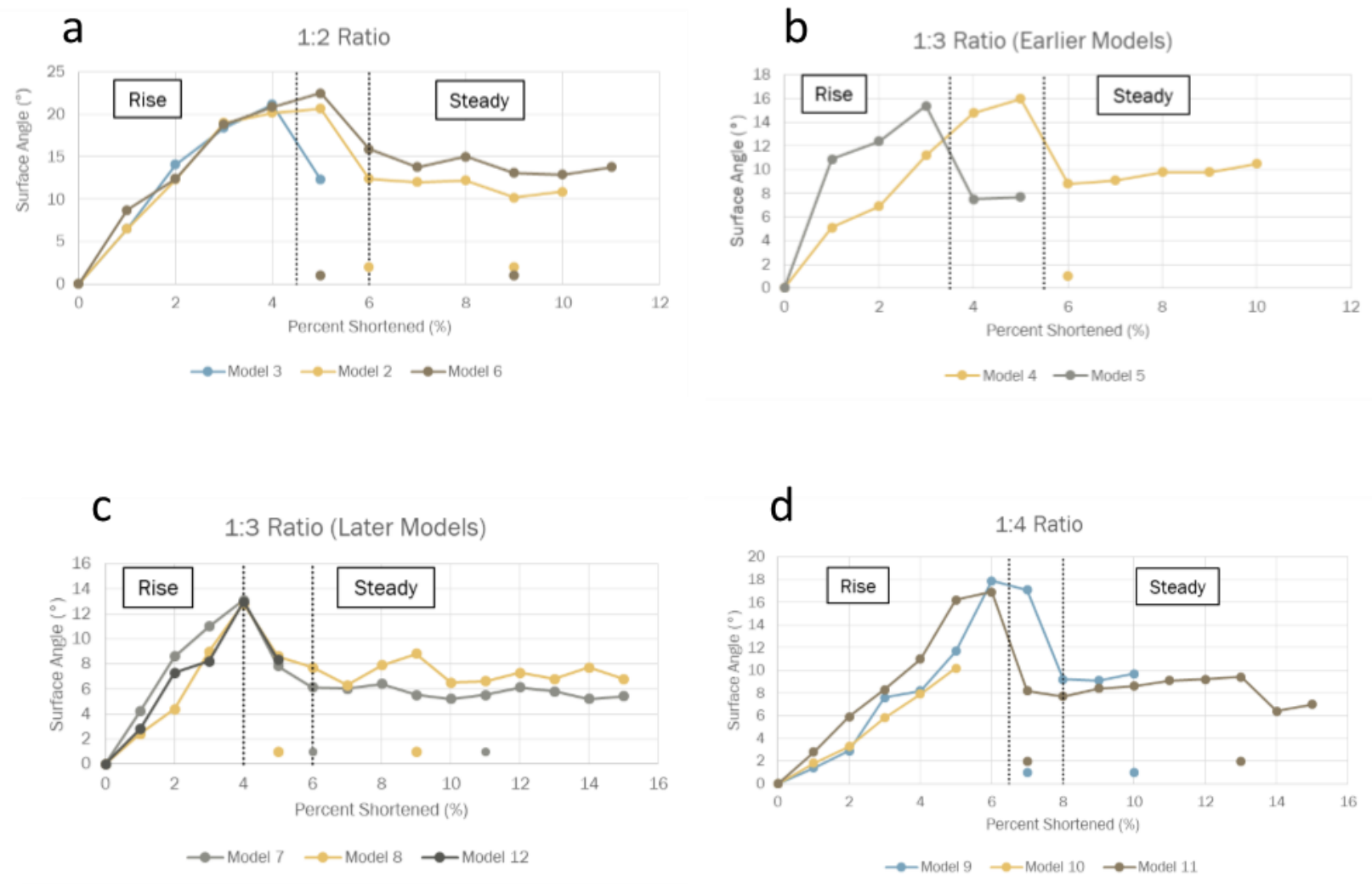
Figure 3: Final configurations of models 3, 2 and 6 from the 1:2 series. A, c, and e show the final photographs, which have been artificially lightened to show the structure more clearly. $B, d$, and f show line drawings of the structures and the grey shaded area is the silicon layer.
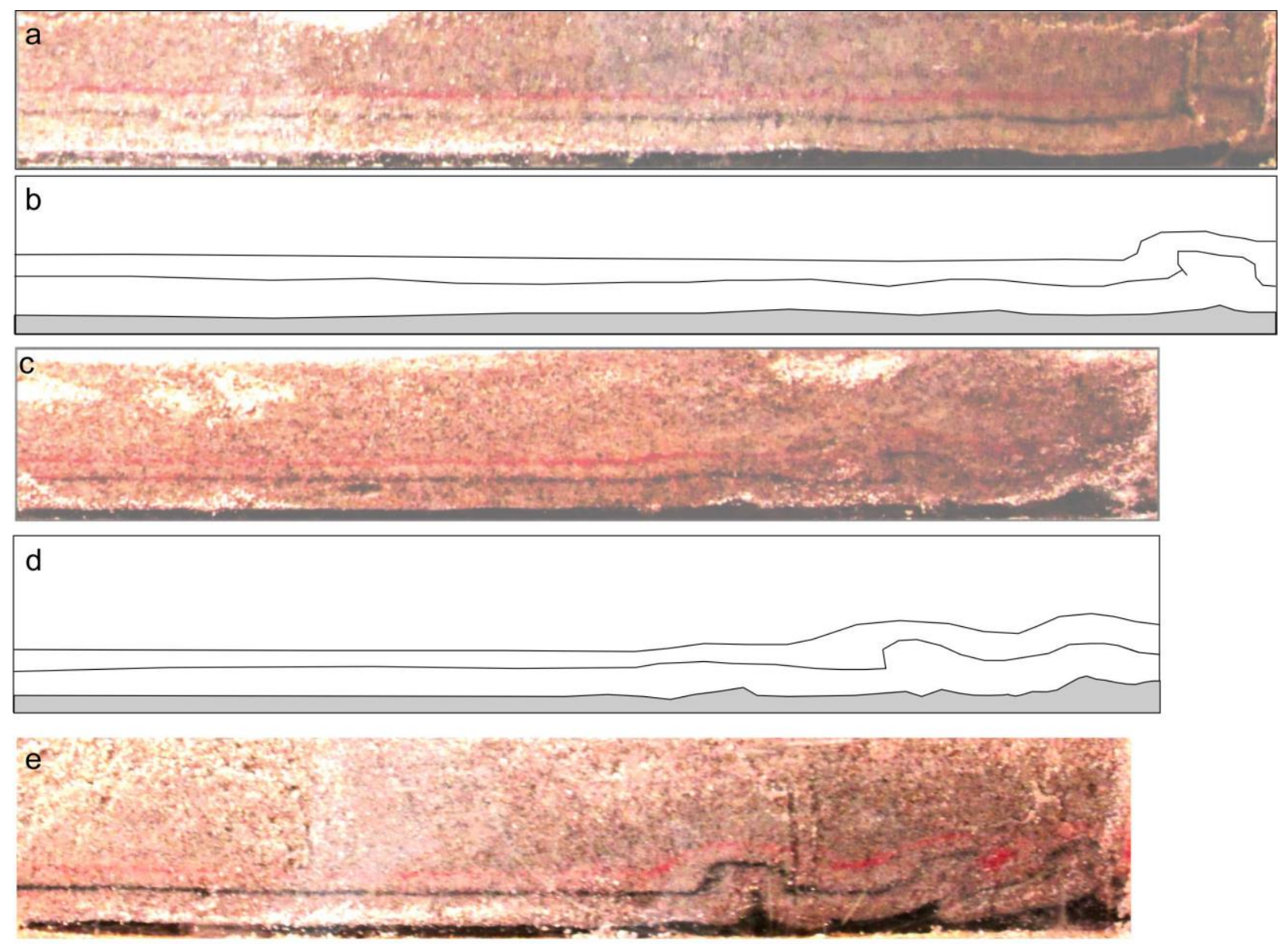

f

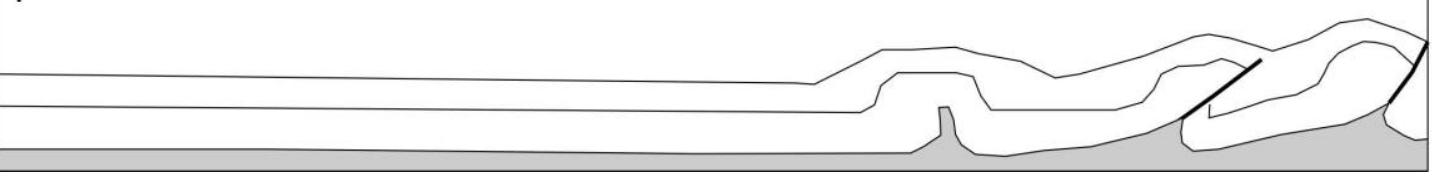


Figure 4: Final configurations of models 4,8 and 12 from the 1:3 series. A, c, and e show the final photographs, which have been artificially lightened to show the structure more clearly. B, $d$, and f show line drawings of the structures and the grey shaded area is the silicon layer.

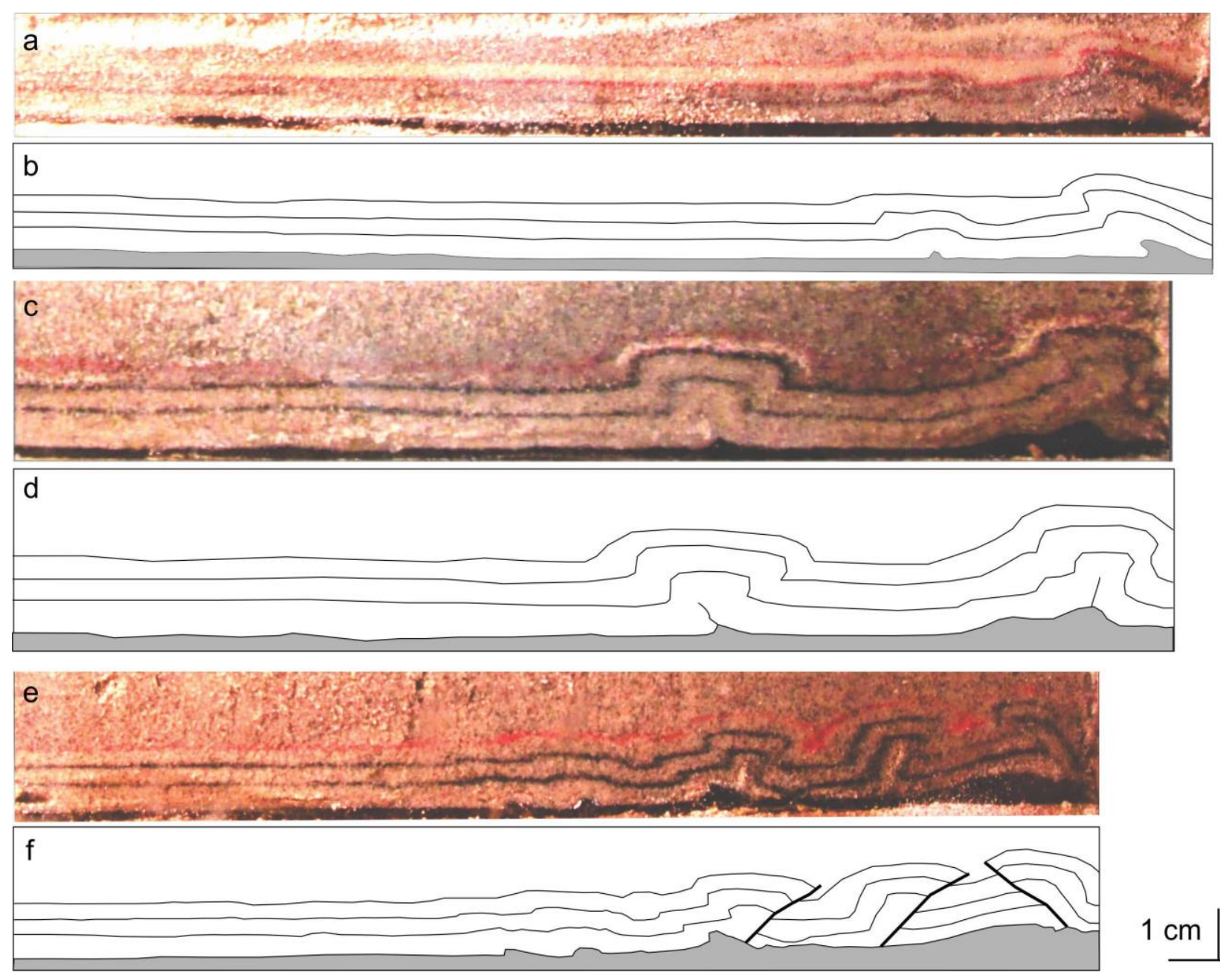


Figure 5: Final configurations of models 9,10 and 11 from the 1:4 series. A, c, and e show the final photographs. $B, d$, and $f$ show line drawings of the structures and the grey shaded area is the silicon layer.
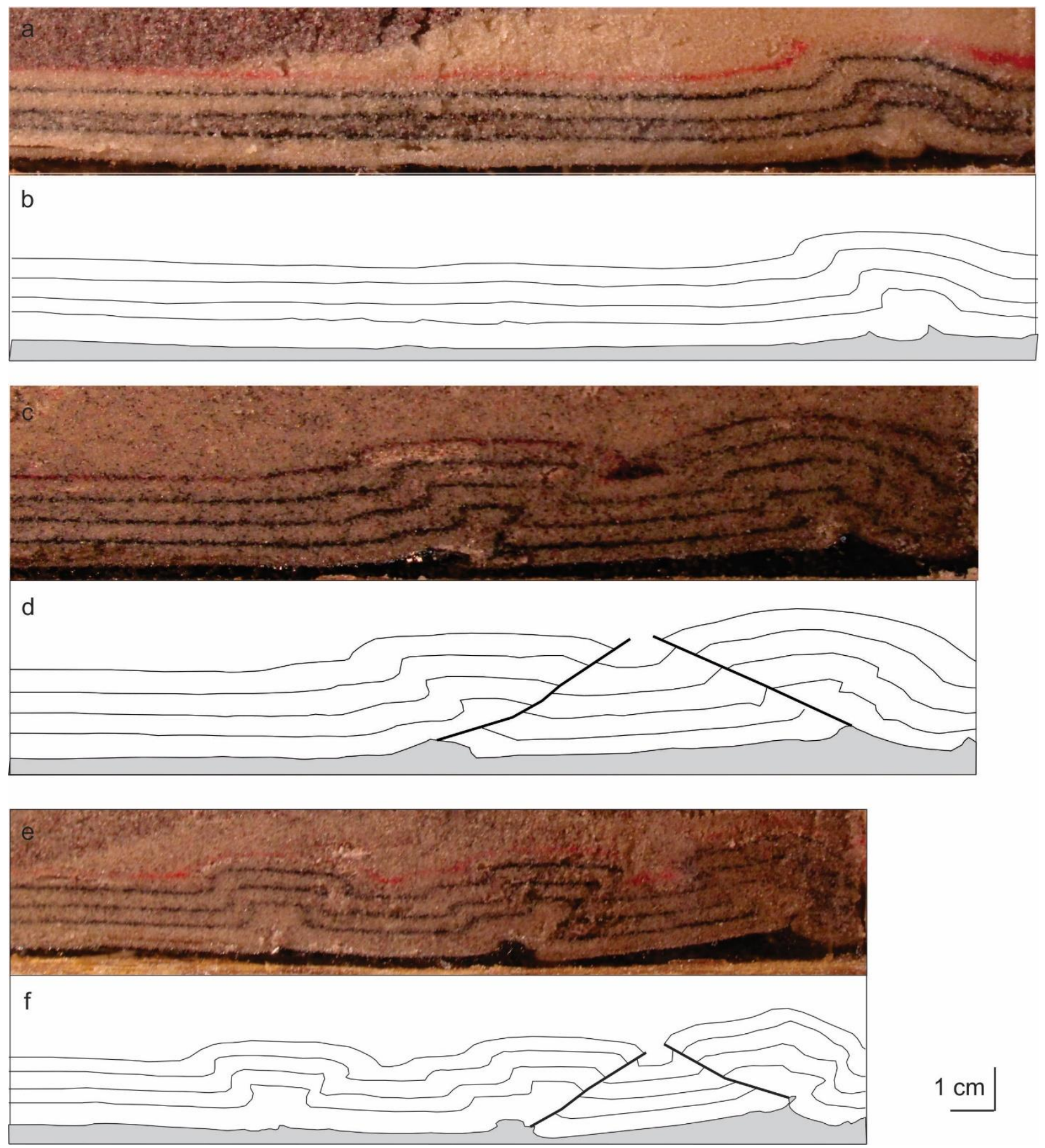

$1 \mathrm{~cm}$ 
Figure 6: Cross-section digitized after McQuarrie (2004) showing the structure of the Fars Zone, Zagros Simply Folded Belt, Iran. This region is predicted to have between $36-57 \mathrm{~km}$ additional shortening due to PS based on the results of this study, to accommodate the development of the critical taper in this system.
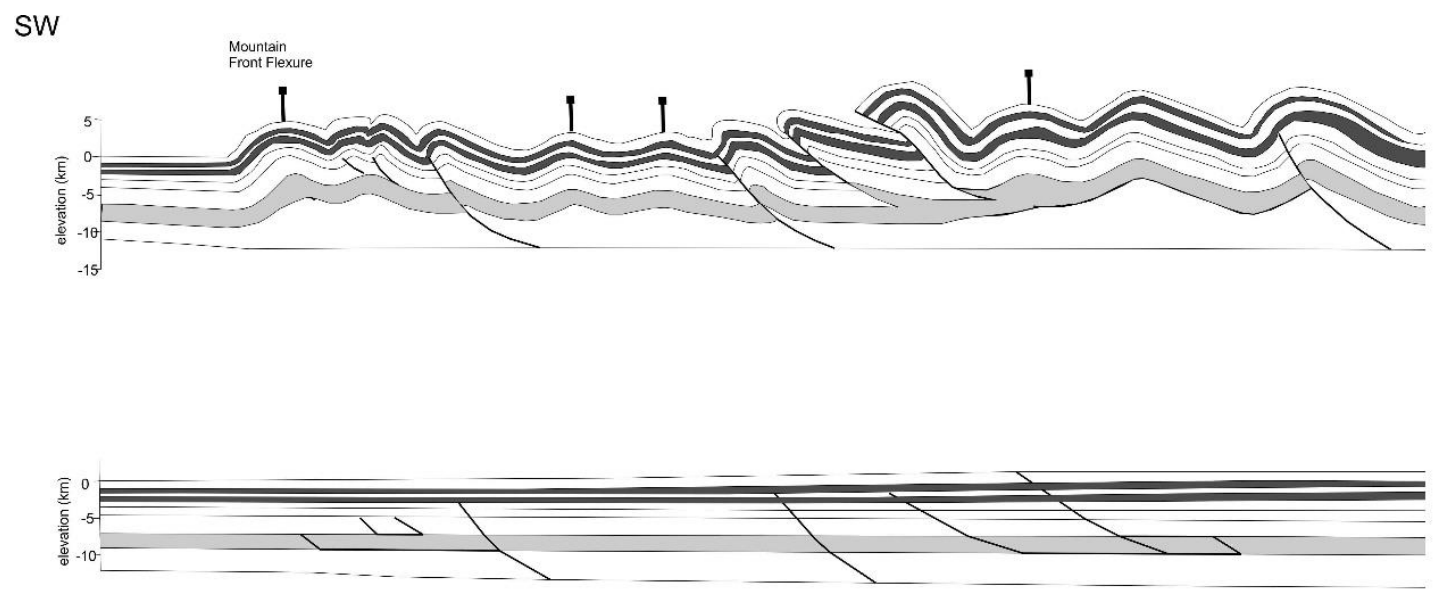

NE

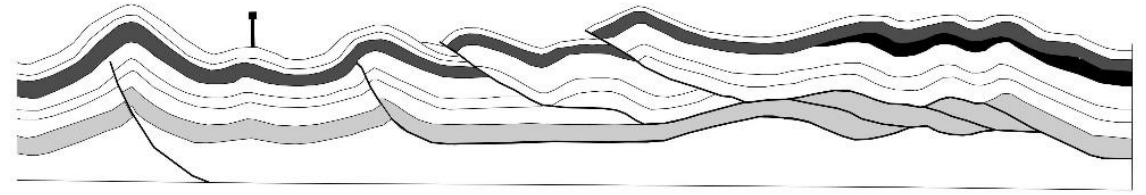

$67 \mathrm{~km}$ tectonic shortening

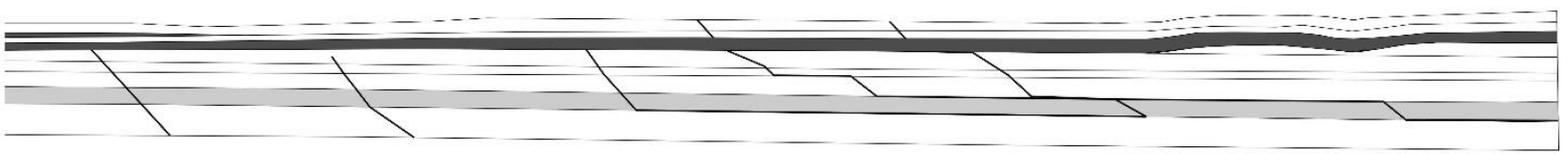

$50 \mathrm{~km}$ 
Figure 7: Penetrative strain in the model series. a) average penetrative strain in the three model series from this study, with (b) figure 10 from Lathrop and Burberry (2017) reproduced for comparison.

a

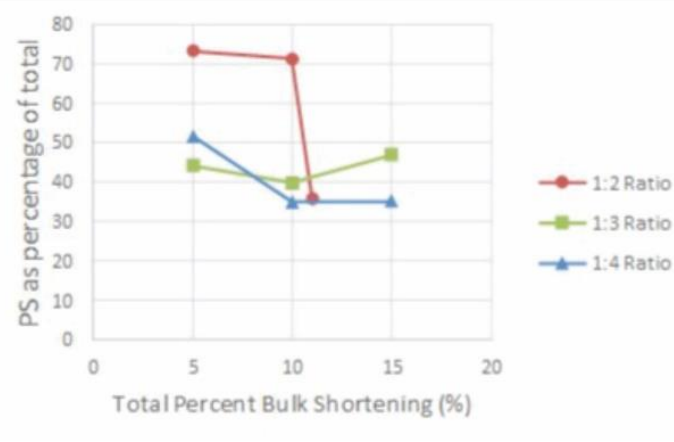

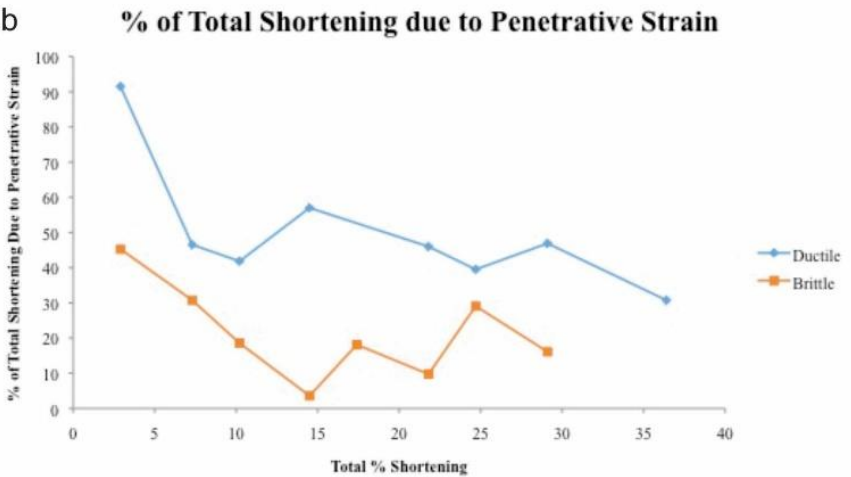

